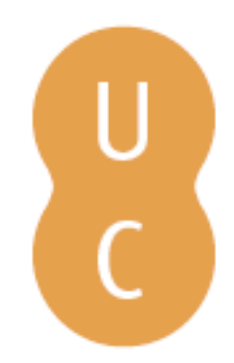

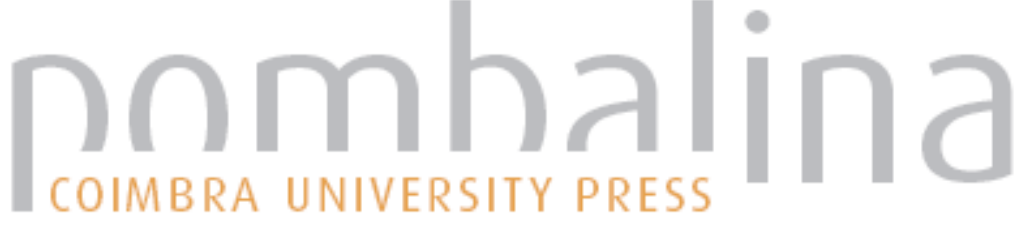

\section{Fronteiras da cosmologia: os primeiros instantes do universo}

\author{
Autor(es): $\quad$ Reeves, Hubert
}

Publicado por: Imprensa da Universidade de Coimbra; Gradiva

URL

persistente: URI:http://hdl.handle.net/10316.2/32665

DOI: $\quad$ DOI:http://dx.doi.org/10.14195/978-989-26-0389-6_8

Accessed : $\quad$ 26-Apr-2023 05:17:18

A navegação consulta e descarregamento dos títulos inseridos nas Bibliotecas Digitais UC Digitalis, UC Pombalina e UC Impactum, pressupõem a aceitação plena e sem reservas dos Termos e Condições de Uso destas Bibliotecas Digitais, disponíveis em https://digitalis.uc.pt/pt-pt/termos.

Conforme exposto nos referidos Termos e Condições de Uso, o descarregamento de títulos de acesso restrito requer uma licença válida de autorização devendo o utilizador aceder ao(s) documento(s) a partir de um endereço de IP da instituição detentora da supramencionada licença.

Ao utilizador é apenas permitido o descarregamento para uso pessoal, pelo que o emprego do(s) título(s) descarregado(s) para outro fim, designadamente comercial, carece de autorização do respetivo autor ou editor da obra.

Na medida em que todas as obras da UC Digitalis se encontram protegidas pelo Código do Direito de Autor e Direitos Conexos e demais legislação aplicável, toda a cópia, parcial ou total, deste documento, nos casos em que é legalmente admitida, deverá conter ou fazer-se acompanhar por este aviso.

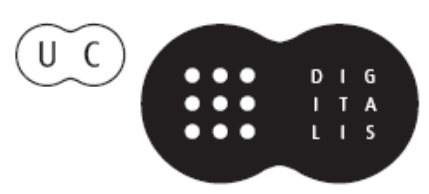


C I E N C I A I B E R T A

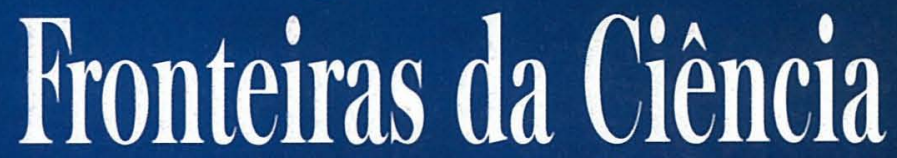

Desenvolvimentos Recentes - Desafios Futuros

RUI FAUSTO • CARLOS FIOLHAIS • JOÃO FILPE QUURRÓ

Coordenadores

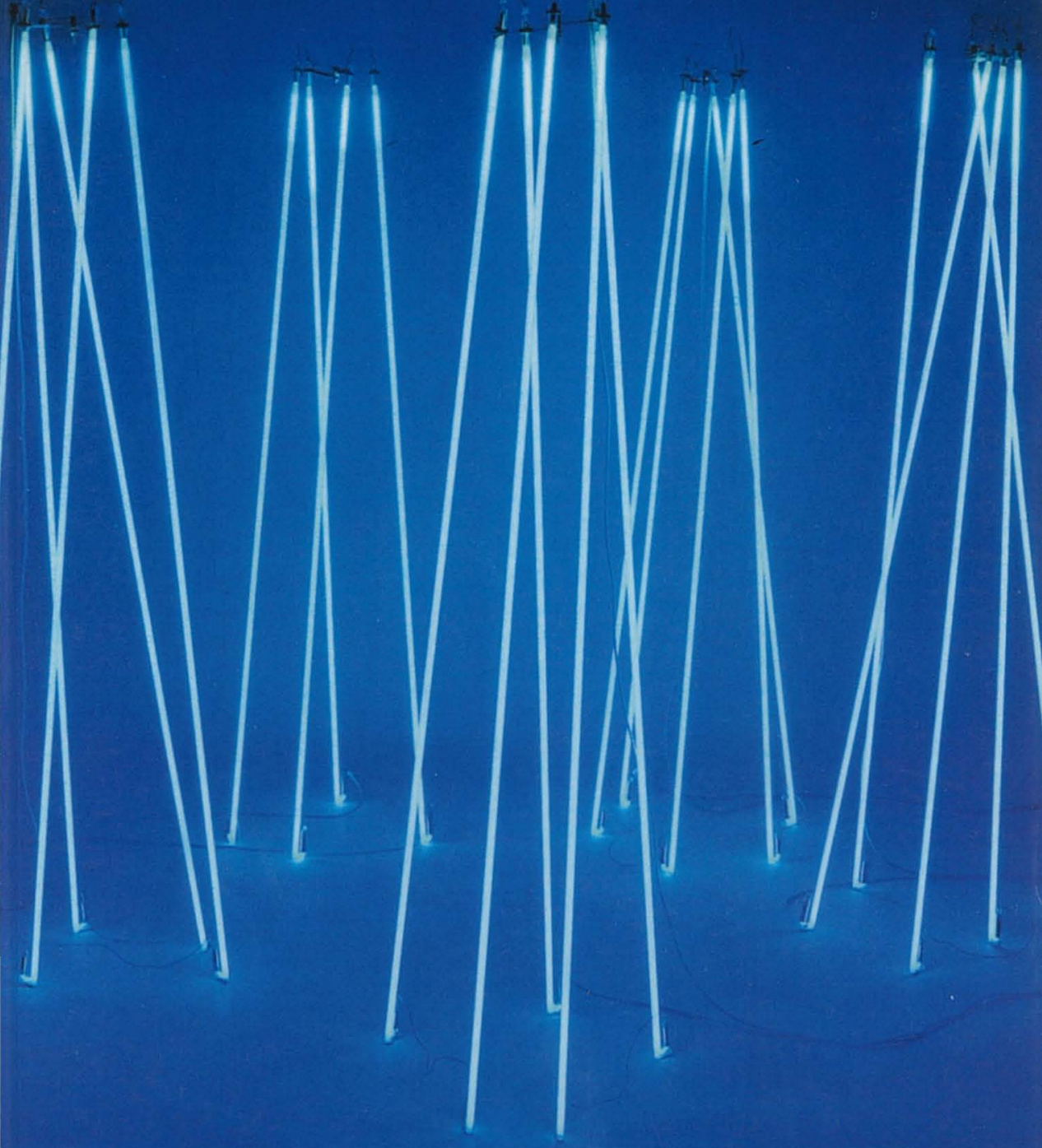

gradiva - Imprensa da Universidade de Coimbra 
(Página deixada propositadamente em branco) 


\section{RUI FAUSTO, CARLOS FIOLHAIS JOÃO FILIPE QUEIRÓ \\ Coordenadores}
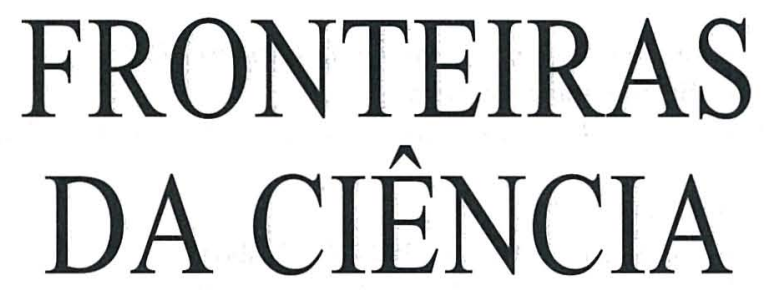

Desenvolvimentos Recentes Desafios Futuros 
(C) Gradiva - Publicações, L. da / Imprensa da Universidade de Coimbra, 2003 Coordenação editorial: Rui Fausto, Carlos Fiolhais e João Filipe Queiró Tradução: Jean Burrows, Vivien Burrows, Rui Fausto, Carlos Fiolhais e João Filipe Queiró

Revisão do texto: Isabel Pedrome

Capa: António Barros [Imprensa da Universidade. Coimbra], sobre imagem de «Águas Vivas», escultura de Silvestre Pestana, 2001

Foto: António Alves; Infografia: ESTÍMULUS [design]; Cortesia: Galeria Alvarez-Arte Contemporânea

Paginação: António Resende e Paula Isabel Jorge

Impressão e acabamento: G.C. - Gráfica de Coimbra, L. ${ }^{d a}$

Reservados os direitos para Portugal por:

Gradiva - Publicações, L. ${ }^{\text {da }}$ e Imprensa da Universidade de Coimbra

Gradiva - Publicações, L.da

Rua Almeida e Sousa, 21, r/c, esq.•1399-041 Lisboa

Telefs. $213974067 / 8 \cdot 213971357 \cdot 213953470$

Fax $213953471 \cdot$ Email: gradiva@ip.pt

URL: http://www.gradiva.pt

Imprensa da Universidade de Coimbra

Rua Antero de Quental, 195 • 3000-033 Coimbra

Telefs. 351239853110

Fax 3512398531 19・e-mail: fjrpress@ci.uc.pt

URL: http://www.imp.uc.pt

ISBN: 972-662-923-3

1." edição: Agosto de 2003

Depósito legal n. ${ }^{\circ} 199$ 463/2003 
Hubert Reeves

Centre Nationale

de la Recherche Scientifique

de Paris

França

\section{Fronteiras da cosmologia: os primeiros instantes do universo}

Tentarei esclarecer o significado da expressão primeiros instantes do universo que aparece no título. Durante muito tempo, pelo menos no seio da comunidade científica, acreditou-se que o universo seria interminável e imutável. Tentarei mostrar como, ao longo do século XX, várias observações científicas demonstraram que o universo não existiu desde sempre e se encontra em rápida evolução. Desenvolverei os aspectos principais determinados por essa evolução.

A figura 1 é uma fotografia do nosso cosmos observado à maior escala jamais alcançada. Esta fotografia foi tirada pelo telescópio Hubble, montado no espaço para evitar as interferências devidas à atmosfera da Terra e permitir a detecção dos objectos mais distantes do universo. Nela podemos observar galáxias, galáxias por todo o lado! Algumas delas estão próximas de nós (talvez a uma centena de milhões de anos-luz ${ }^{1}$ ). Os pontos mais pequenos correspondem aos objectos mais distantes, situados a alguns milhares de milhões de anos-luz do sistema solar. O universo é efectivamente muito grande!

${ }^{1}$ Um ano-luz é aproximadamente igual a $9,5 \times 10^{12} \mathrm{~km}$. 
Em cada uma destas galáxias existe quase um bilião de estrelas e alguns sistemas planetários. Podemos imaginar que alguns destes são habitados por seres inteligentes, que possuem universidades que celebram os seus aniversários através da realização de conferências, onde a assistência poderia estar a observar uma imagem semelhante a esta e na qual a nossa Via Láctea corresponderia apenas a um pequeno ponto...

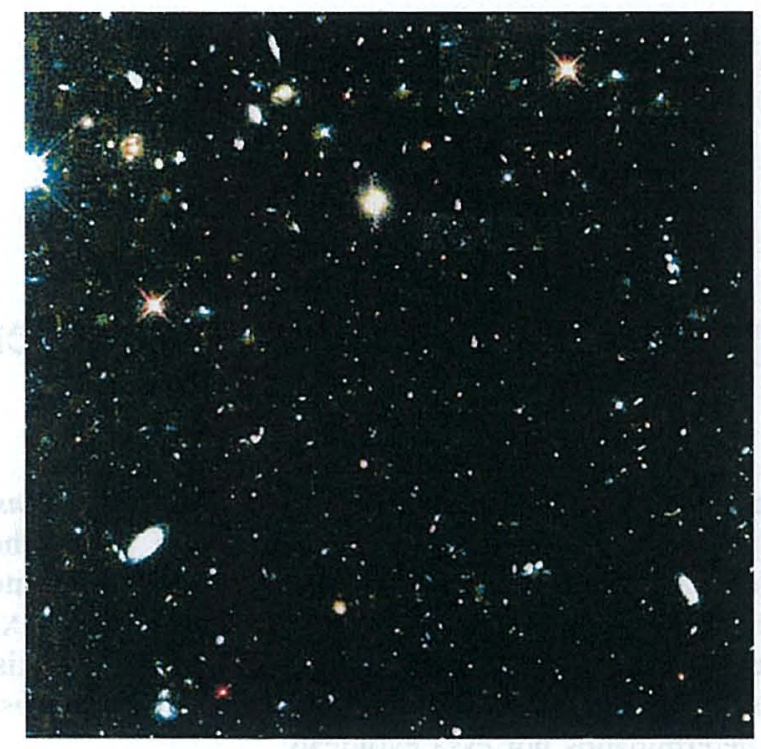

Fig. 1 - Fotografia do espaço obtida pelo telescópio espacial Hubble. Nela podem ver-se as galáxias mais distantes do universo

A pergunta sobre se o universo é infinito no espaço é uma questão ainda sem resposta. Existem aspectos relacionados com a topologia do universo que ainda nos escapam. Irei agora apresentar-vos algumas das razões por que pensamos que o universo não foi sempre igual ao longo do tempo.

Em primeiro lugar deve referir-se a importante descoberta feita por Edwin Hubble, o astrónomo norte-americano que deu o seu nome ao telescópio espacial, na segunda década do século Xx. Hubble notou que as galáxias, tal como as observamos, não estão imóveis, mas se afastam 
umas das outras. A figura 2 ilustra esta situação. Imagine-se que o ponto central da figura é o olho do senhor Hubble e que todos os restantes são galáxias. Hubble observou que as galáxias se movem de uma forma particular. As galáxias mais próximas movem-se mais lentamente (na figura, uma seta menor significa uma velocidade menor), enquanto as mais afastadas se movem mais rapidamente. A expressão expansão do universo significa simplesmente que, se se considerarem duas galáxias quaisquer, estas se afastam constantemente uma da outra. A partir desta observação pode concluir-se imediatamente que, no passado, o universo era mais denso e que se tem tornado progressivamente menos denso com o passar do tempo.

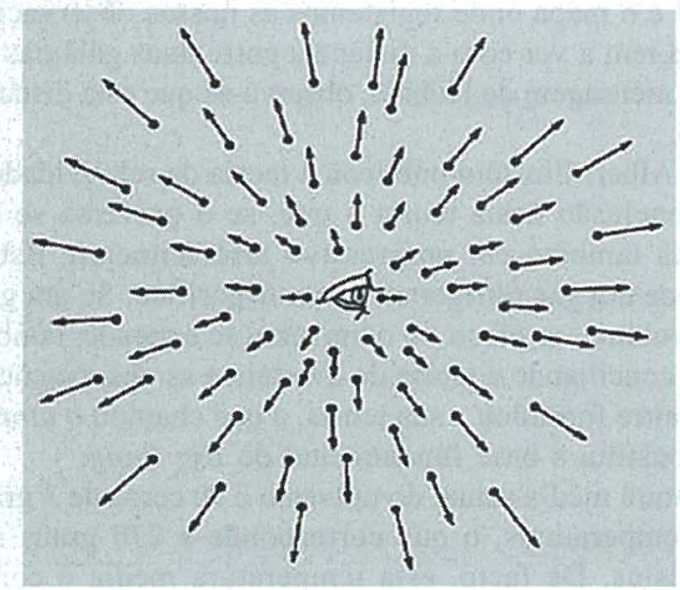

Fig- 2 - Movimento das galáxias. O olho de Edwin Hubble descobriu que todas as galáxias (pontos) se afastam de nós. As velocidades (setas) crescem com a distância

A figura 3 permite descrever de forma evidente o modo como actualmente os cosmólogos exploram o passado do universo. Nós não começamos por afirmar no início dos tempos deu-se o Big Bang. Na verdade, não sabemos nada sobre isso. Apenas sabemos que o universo está em evolução, o que nos permite explorar o continente do tempo. Comecemos então por aquilo que conhecemos, nomeadamente o presente, e desloquemo-nos para trás no tempo, tentando descobrir como o universo foi no passado. 
Eu gosto de comparar o trabalho dos astrofísicos com o dos exploradores nos séculos passados. Na exposição mundial de Lisboa, dedicada aos oceanos e aos descobrimentos (Expo 98), vi um mapa geográfico antigo da América do Sul. No centro do mapa, numa área em branco, estavam escritas as palavras Terra incognita. Estas palavras significavam para os geógrafos de então: nós ainda não visitámos estes territórios. A exploração de um continente foi um desafio progressivo, em que os exploradores partiram do litoral e penetraram progressivamente os recantos mais recônditos do interior. Isto é muito parecido com a forma como exploramos o passado do universo: começamos do presente e tentamos dirigir-nos para o passado e obter informações sobre ele. Para obter essa informação, precisamos de realizar algumas observações.

A figura 3 é o mapa onde registamos as nossas observações. A escala das ordenadas tem a ver com a distância entre duas galáxias remotas. De acordo com a mensagem de Hubble, observa-se que esta distância aumenta com o tempo.

Em 1915, Albert Einstein publicou a teoria da relatividade geral. Uma importante conclusão desta teoria é que, se o universo se encontra em expansão, está também em progressivo arrefecimento. Esta situação é semelhante à de um gás refrigerante num frigorífico. Se um gás sofre uma expansão de volume, arrefece; se o universo se expande, também arrefece.

Em 1928, conciliando a teoria de Einstein e as observações de Hubble, Georges Lemaître formulou a sua teoria, a que chamou o átomo primitivo. Esta teoria constitui a base fundamental do Big Bang.

A temperatura média actual do universo é de cerca de 3 graus na escala absoluta de temperaturas, o que corresponde a 270 graus negativos na escala de Celsius. De facto, esta temperatura média é conhecida com bastante precisão: ela é exactamente 2,736 graus.

Deste modo, graças a Einstein e a Lemaître, aprendemos que o universo experimenta duas alterações fundamentais: expande-se (a densidade decresce) e arrefece (a temperatura diminui).

Nesta altura entra em cena o terceiro actor astrofísico, o russo George Gamov. Em 1948, ele especulou nos seguintes termos: Suponhamos que a teoria é verdadeira e suponhamos que podemos regredir no tempo até atingirmos temperaturas extremas. Nesta situação a densidade da radiação torna-se maior do que a densidade de matéria e o universo é dominado pela luz. Gamov afirmou então: $O K$, suponhamos que existiu um instante algures no passado, quando o universo era essencialmente composto por radiação, em que ocorreu um grande relâmpago. Bem, o que aconteceu a este relâmpago de então para cá? Depois de efectuar uma série de cálculos, Gamov chegou à conclusão de que a luz associada 
àquele fenómeno não podia ter desaparecido totalmente. Uma parte dela ainda deveria poder observar-se nos nossos dias. Fez então uma previsão: Se o Big Bang ocorreu de facto, deve ainda permanecer homogeneamente disperso no universo um fundo de radiação térmica, que devemos ser capazes de detectar, apesar de ele actualmente ser muito fraco. Esta radiação remanescente seria uma espécie «fóssil» dos primeiros dias de existência do universo.

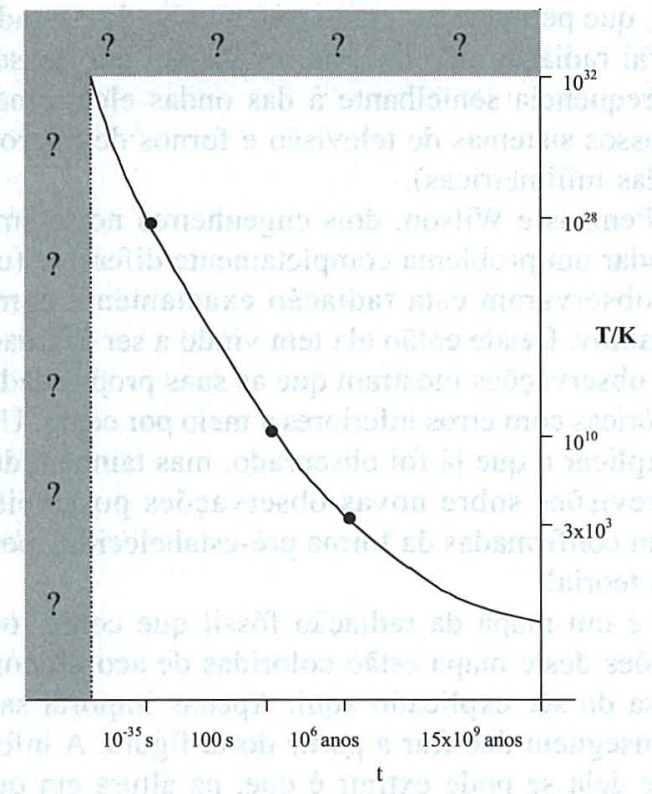

Fig. 3 - O nosso mapa do passado do universo. Em ordenadas estão as temperaturas. Os acontecimentos cruciais, descobertos a partir dos seus fósseis, estão assinalados no eixo das abcissas (o tempo está em segundos e em anos, contado a partir do Big Bang.

Em cosmologia, usamos muitas vezes esta noção de «fóssil», tal como os arqueólogos fazem para descrever como os seres humanos se comportavam há milhares de anos atrás. Os fósseis cosmológicos são radiações e átomos que nos mostram como o universo era na altura em que se formaram. Da mesma forma, os arqueólogos são capazes de 
conhecer alguma coisa sobre as civilizações de Cro-Magnon ou de Neanderthal se tiverem a sorte de encontrar vestígios destas civilizações extintas.

Apresentemos agora as seguintes questões: visto que o universo está a arrefecer, qual terá sido a sua temperatura no passado? Poderemos observar fósseis que nos comprovem que ele atingiu, num certo instante, uma dada temperatura? Usaremos o nosso mapa do tempo para registar as nossas observações.

O nosso primeiro fóssil é, de acordo com a previsão de Gamov, uma radiação fóssil, que permaneceu como testemunho do passado «brilhante» do universo. Tal radiação não deveria ser visível aos nossos olhos, mas possuir uma frequência semelhante à das ondas electromagnéticas que usamos nos nossos sistemas de televisão e fornos de microondas (ondas de rádio e ondas milimétricas).

Em 1965, Penzias e Wilson, dois engenheiros norte-americanos que estavam a estudar um problema completamente diferente (comunicações por satélite), observaram esta radiação exactamente como tinha sido prevista por Gamov. Desde então ela tem vindo a ser estudada em grande pormenor e as observações mostram que as suas propriedades se ajustam às previsões teóricas com erros inferiores a meio por cento. Uma boa teoria deve não só explicar o que já foi observado, mas também deve ser capaz de efectuar previsões sobre novas observações possíveis. Se as suas previsões forem confirmadas da forma pré-estabelecida, pode afirmar-se que é uma boa teoria!

A figura 4 é um mapa da radiação fóssil que cobre todo o céu. As diferentes regiões deste mapa estão coloridas de acordo com um código que não precisa de ser explicado aqui. Apenas importa saber o que os astrofísicos conseguem decifrar a partir desta figura. A informação mais importante que dela se pode extrair é que, na altura em que a radiação foi emitida, não existiam ainda galáxias, estrelas, planetas ou mesmo moléculas e átomos. O universo era uma sopa homogénea constituída por aquilo a que chamamos partículas elementares. Era então extremamente quente (3000 graus), denso (cerca de um bilião de vezes mais denso do que actualmente) e - e o que é o mais importante para nós completamente caótico, no sentido em que não existiam quaisquer sistemas organizados.

É instrutivo comparar as partículas elementares com as letras do alfabeto que servem de base à nossa literatura escrita. As palavras são conjuntos de letras, as frases são combinações de palavras e por aí adiante no que diz respeito aos parágrafos, capítulos, livros, bibliotecas, etc. 
O nosso universo actual é altamente organizado. Existem estruturas organizadas a todas as escalas: galáxias, estrelas, planetas, seres vivos, moléculas, átomos, etc. Naquela altura não existia nada disto. Existiam apenas «letras» e não palavras, frases e por aí fora. Aqui deparamos com uma terceira diferença entre o universo passado e presente. $\mathrm{O}$ universo actual é frio, escuro (a noite é escura) e altamente organizado. O universo naquela altura era quente e denso, mas completamente desorganizado. Estas diferenças contam a história do universo; contam como ao longo deste arrefecimento as partículas elementares se combinaram para formar átomos, moléculas, planetas, estrelas, galáxias e como na Terra, por fim, evoluiu a vida.

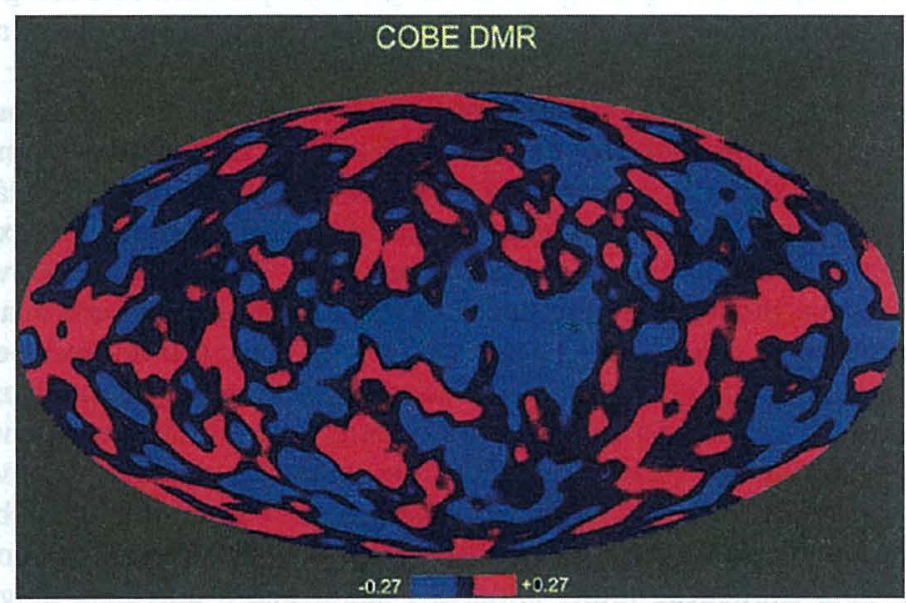

Fig. 4-A fotografia mais antiga do nosso universo, abarcando a totalidade do céu. Esta fotografia foi tirada pelo telescópio espacial COBE. A elipse contém a imagem da abóbada celeste distendida sobre um plano. Os dados do satélite COBE estão ai inscritos (subtraídos da variação da temperatura gerada pelo movimento da Terra). As variações residuais, da ordem do centésimo de milésimo, serviram para mostrar a "granularidade» da matéria cósmica no momento da emissão da radiação fóssil (foto da NASA).

Vimos então que estas três diferenças constituem a parte mais importante da nossa história. Antes de avançarmos mais neste assunto, continuemos a deslocar-nos no sentido do passado. Voltemos de novo ao nosso mapa. 
Vou falar-vos agora de três fósseis. Cada um deles é capaz de nos dizer qualquer coisa sobre o passado do universo.

Em primeiro lugar, temos a radiação fóssil da figura 4, vulgarmente designada por radiação de fundo de $3 K$ (K, kelvin, a unidade da escala absoluta de temperaturas). Esta radiação fóssil foi emitida num momento em que o universo se encontrava a uma temperatura de 3000 graus. Para passar de 3000 para 3 graus foram necessários cerca de dez biliões de anos. Este é o nosso primeiro passo. Observe-se como progredimos. Identificamos um fóssil e interpretamo-lo de seguida. Este primeiro fóssil diz-nos que, no passado, o universo atingiu pelo menos a temperatura de 3000 graus. Se o leitor não aceitar esta interpretação pode fazer a sua própria, mas até agora nenhuma outra alcançou mais sucesso que a previsão simples do Big Bang: se se atingiu a temperatura de 3000 graus, deveria existir uma radiação fóssil exactamente como nós a observamos actualmente...

Consideremos agora um outro fóssil: os átomos de hélio. Sabemos que as estrelas fabricam hélio, que o Sol produz hélio, mas sabemos também que a maioria do hélio foi formado antes das estrelas. Quando as galáxias nasceram, antes de ter tido lugar qualquer evolução das estrelas, existia uma distribuição homogénea de hélio no universo. De onde é que ele veio? Se estivermos prontos a admitir que o universo atingiu, numa certa ocasião, temperaturas de pelo menos 10 mil milhões de graus $(10$ mil milhões de graus é uma temperatura típica de ocorrência de reacções nucleares), teremos uma explicação simples para o facto de a relação actual entre o número de átomos de hélio e de hidrogénio ser de um para dez. A previsão não é só qualitativa, mas também quantitativa - funciona muito bem!

Este é o nosso fóssil número dois - de onde surgiram os átomos de hélio? Uma explicação muito simples é supor que o universo, nalguma ocasião, atingiu a temperatura de pelo menos 10 mil milhões de graus. Isto é suficiente para explicar quantitativamente a abundância dos átomos de hélio e também de outros átomos como os de deutério (hidrogénio pesado), hélio-3 e lítio-7. Estes acontecimentos tiveram lugar cerca de um milhão de anos antes da emissão da radiação fóssil.

De regresso ao nosso mapa (figura 3 ), podemos verificar que a radiação fóssil nos levou até aos 3000 graus, enquanto os átomos de hélio nos fizeram atingir os 10 mil milhões de graus. À medida que nos deslocamos para trás no tempo, atingimos temperaturas cada vez mais elevadas e os acontecimentos dão-se cada vez mais rapidamente.

Existe um terceiro fóssil que se relaciona com aquilo a que chamamos antimatéria. De acordo com a física nuclear clássica, deveria existir no universo tanta antimatéria como matéria. Contudo, actualmente não existe 
praticamente nenhuma antimatéria, se exceptuarmos aquela que nós próprios produzimos nos aceleradores de partículas. Levanta-se então a questão: porque há tão pouca antimatéria no universo? Se estivermos dispostos a admitir que o universo atingiu, nalguma ocasião, uma temperatura de pelo menos $10^{28}$ graus (um um seguido de 28 zeros!) é possível responder a esta pergunta. Àquela temperatura ocorreram uma série de fenómenos físicos que tiveram como consequência que a antimatéria, presente anteriormente, desaparecesse do universo. Não entrarei aqui nos pormenores relativos a estes acontecimentos, mas saliento esta consequência importante. Podemos então explicar simplesmente a ausência de antimatéria se supusermos que algures no tempo o universo atingiu os $10^{28}$ graus. Isto aconteceu um minuto antes do nascimento dos átomos de hélio.

No nosso mapa do tempo (figura 3), podemos colocar as nossa marcas: 3000 graus - radiação fóssil; 10 mil milhões de graus — hélio; $10^{28}$ graus — ausência de antimatéria.

Volto a repetir: para conhecer qualquer coisa sobre os primeiros tempos do universo temos de encontrar fósseis (radiação fóssil, hélio, ausência de antimatéria). Eles dão-nos informações sobre o estado do cosmos (temperatura, densidade, etc.) em diferentes períodos da sua história.

Poderemos regredir ainda mais no tempo? Neste ponto experimentamos uma dificuldade maior relativamente ao estado actual do nosso conhecimento no domínio da física. Sabemos que, se atingirmos uma situação na qual a temperatura é superior a $10^{32}$ graus, toda a nossa física colapsa. Não sabemos como é que a matéria se comporta a temperaturas acima desta, nem mesmo se se poderão ainda usar os conceitos fundamentais de tempo e temperatura. O problema é que nesta situação extrema a teoria da relatividade geral entra em conflito com a mecânica quântica. Por outras palavras, ninguém foi ainda capaz de desenvolver uma teoria quântica gravitacional. Atingimos então a terra incognita da física. Neste momento não dispomos de ferramentas para explorar este território. Muita gente tem vindo a tentar formular uma teoria quântica da gravidade, mas com pouco sucesso até agora. Esta é pois a fronteira actual do nosso conhecimento: sabemos que o universo atingiu pelo menos a temperatura de $10^{28}$ graus, mas não podemos ir mais longe e explorar a terra incognita que fica para lá deste ponto. Apesar disso, a física encontra-se em progresso permanente e pode ser que um dia algum jovem estudante nos surja com uma teoria quântica da gravidade. Nessa altura poderemos ser capazes de recuar ainda mais no tempo. Por agora estamos limitados por esta ausência de uma teoria física fundamental. 
Resumamos sucintamente o que foi referido até este ponto. $\mathrm{O}$ universo não é estático, sofrendo modificações de três tipos essenciais: está a arrefecer, a ficar mais escuro e menos denso e também a tornar-se mais organizado à medida que o tempo passa.

Blaise Pascal, um filósofo do século XVII, observou que o corpo humano se situa numa escala entre dois infinitos: o infinitamente grande $e$ o infinitamente pequeno. A estes adicionamos agora uma terceira escala: a escala da complexidade. Esta escala está relacionada com o aparecimento da vida, incluindo células, organismos e ecossistemas. A figura 5 mostra estas três escalas. Deslocando-nos para cima, encontramos planetas, estrelas, galáxias, o universo. Deslocando-nos para baixo, encontramos moléculas, átomos, protões, quarks e electrões. Movendo-nos para a direita, encontramos células, plantas, animais.

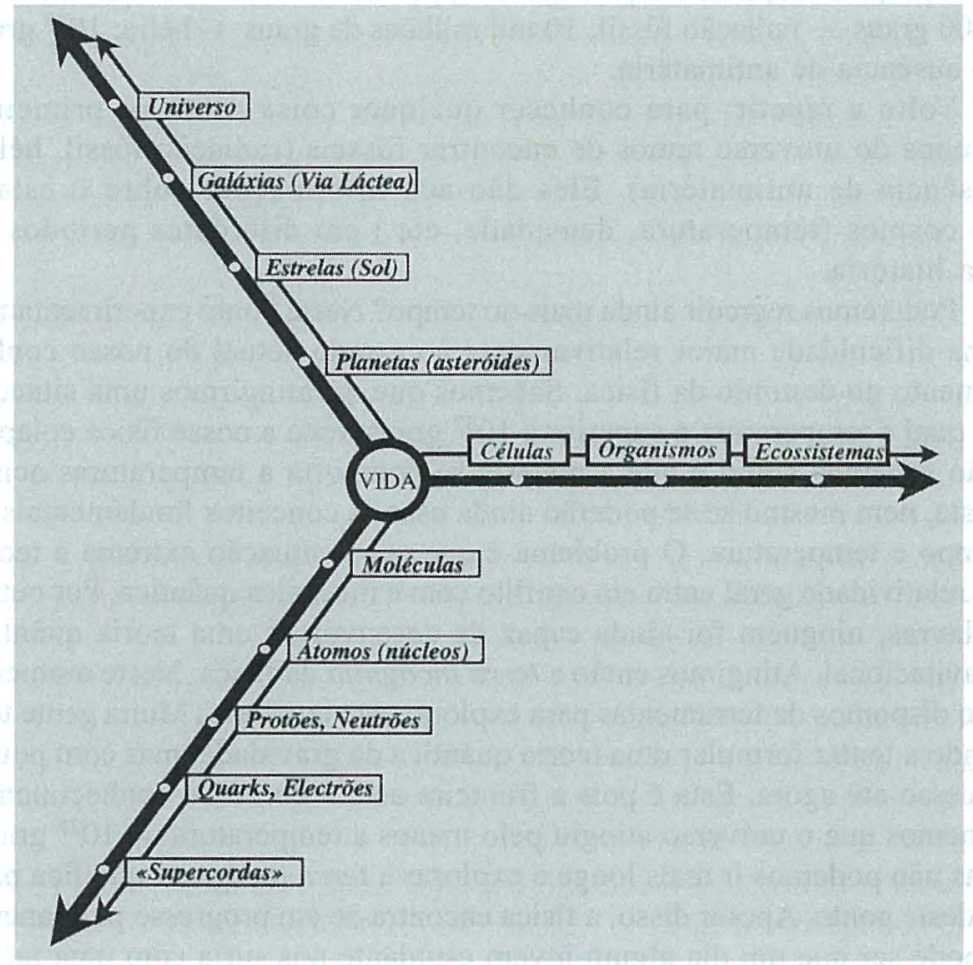

Fig. 5-As três escalas que descrevem a evolução do universo. O tempo cresce da esquerda para a direita. A partir das interacções das escalas do muito grande e do muito pequeno surge a escala do complexo. 
Notemos uma relação muito interessante entre estas escalas. A escala da complexidade emerge de uma interacção fecunda entre a escala do muito grande e do muito pequeno. Pelas suas propriedades geométricas e topológicas, o universo como um todo é responsável pela existência de quarks, em primeiro lugar, e de protões e de neutrões, mais tarde. Os átomos agrupam-se para formar estrelas. As moléculas combinam-se à superfície dos planetas.

Esta interacção opera ainda actualmente. O Sol fornece o calor para a vida se poder desenvolver. Conhecemos também uma outra relação interessante entre a vida na Terra e o céu sobre as nossas cabeças. $O$ bombardeamento da Terra por asteróides e cometas tem sido responsável por muitos eventos importantes para a evolução da vida. O diálogo frutuoso entre as escalas do muito grande e do muito pequeno continua hoje em dia através da interacção entre o Sol e os planetas e da interacção dos asteróides e cometas com o decorrer da evolução biológica.

$\mathrm{Na}$ figura 5 o tempo cresce da esquerda para a direita. Podemos fornecer a cronologia dos acontecimentos pelos quais nós vemos a matéria a combinar-se pela interacção entre as duas escalas para dar entidades progressivamente mais complexas. Os primeiros protões surgiram quando o universo existia há 40 milionésimos de segundo, o primeiro núcleo de hélio após alguns minutos. As galáxias começaram a desenvolver-se passados 300000 anos. Na Terra, as primeiras células apareceram há cerca de 3,5 mil milhões de anos, os primeiros organismos há menos de mil milhões de anos, os primeiros mamíferos há cerca de duzentos milhões de anos e o primeiro hominídeo há cerca de 2 milhões de anos (poderão existir outros planetas habitados que tenham seguido diferentes cronologias).

A mensagem mais interessante da ciência actual é talvez a profundidade do nosso relacionamento, enquanto seres humanos, com a totalidade do universo. Nós dependemos da existência prévia das galáxias, estrelas, planetas, etc. A nossa vida, a nossa existência, a nossa presença aqui, nesta ocasião, estão relacionadas com acontecimentos que tiveram lugar numa escala muito grande (milhões e milhares de milhões de anos-luz) e também numa escala muito pequena (bilionésimos de milímetro), numa escala temporal de biliões de anos.

Para dar um exemplo muito simples, que torna esta história, num certo sentido, ainda mais dramática, considerarei dois elementos de comparação. Cada um de nós aqui presentes é feito de quarks e electrões. Para formar um corpo humano são necessários muitos quarks e electrões (o número é um 1 seguido de 29 zeros, $10^{29}$ — variando com o peso da pessoa, mas não muito significativamente...). Estes quarks e electrões, que podemos 
tocar em nós próprios, estiveram presentes no universo primitivo. A diferença fundamental entre o seu estado passado e actual é que naquela altura se encontravam totalmente dissociados. Cada um deles comportava-se de forma semelhante a uma bola numa mesa de bilhar, deslocando-se no espaço disponível e colidindo ocasionalmente com os seus vizinhos. Hoje em dia estão organizados, fazem parte de um sistema sofisticado extraordinariamente complexo: o nosso maravilhoso corpo, no qual cada um deles, localizado precisamente, desempenha um papel particular.

Quando fechamos os olhos e dizemos eu existo, quando tomamos consciência da nossa existência, estamos a realizar um dos actos mais sublimes no universo. Actividades globais, como abrir os olhos e verificar que estamos a participar numa conferência em Coimbra requerem que $10^{29}$ partículas se organizem para formar um ser e isto, por seu lado, requer a existência de galáxias, estrelas, planetas, o fabrico de átomos, moléculas e assim por diante...

Consideremos agora o futuro do universo. Teoricamente, existem dois cenários possíveis. No primeiro, as galáxias continuam a afastar-se umas das outras, indefinidamente, e o universo torna-se progressivamente mais frio. Este é o que normalmente conhecemos por universo aberto ou Big Chill. No segundo cenário, a atracção gravitacional mútua das galáxias é suficiente para as desacelerar, primeiro, e obrigá-las depois a inverter o sentido do seu movimento, levando à sua aproximação progressiva. Neste caso, a temperatura, em vez de diminuir até ao zero absoluto, começará a aumentar de novo. Este cenário corresponde ao universo fechado ou Big Crunch.

No âmbito da teoria da relatividade geral, estes dois cenários são possíveis. Interessa-nos contudo saber qual é o nosso universo: qual destes cenários terá lugar?

Define-se densidade crítica como a densidade do universo que serve de fronteira entre estes dois cenários. Se o universo for muito denso, acabará por se contrair; se não for suficientemente denso, expandir-se-á para sempre: a atracção gravítica não será suficientemente forte para o fazer voltar a contrair. Então a questão fundamental é a seguinte: qual é a densidade do universo? Estamos num universo com densidade superior ou inferior à densidade crítica? As melhores estimativas da densidade apontam para valores de cerca de $3 / 10$ da densidade crítica. Deste modo, as melhores evidências que possuímos (e, naturalmente, em ciência nada, à partida, é certo; podemos sempre ser surpreendidos!) indicam que vivemos num universo que irá arrefecer interminavelmente e nunca mais reaquecerá. Há mesmo sinais de que, em vez de desacelerarem, os movimentos relativos das galáxias estão a acelerar... 
Passarei agora à segunda parte da minha conferência que, devo referir, não é tão agradável. Voltemos à figura 5 , onde podemos observar o crescimento da complexidade: galáxias formando estrelas, átomos e moléculas; nascimento e evolução da vida. Tudo isto parece uma bela história. Mas...

A figura 6 é uma fotografia nocturna da Terra obtida a partir de um satélite. Esta imagem do nosso planeta é a que os cosmonautas vêem. $\mathrm{Na}$ versão colorida da fotografia, o amarelo corresponde à iluminação das cidades e estradas, o vermelho são gases ardentes sobre os poços de petróleo da Península Arábica, Argélia, etc., o púrpura as florestas em chamas em África. A aurora boreal, a azul, sobre o Árctico, é a única região iluminada em resultado de causas que não a acção do homem.

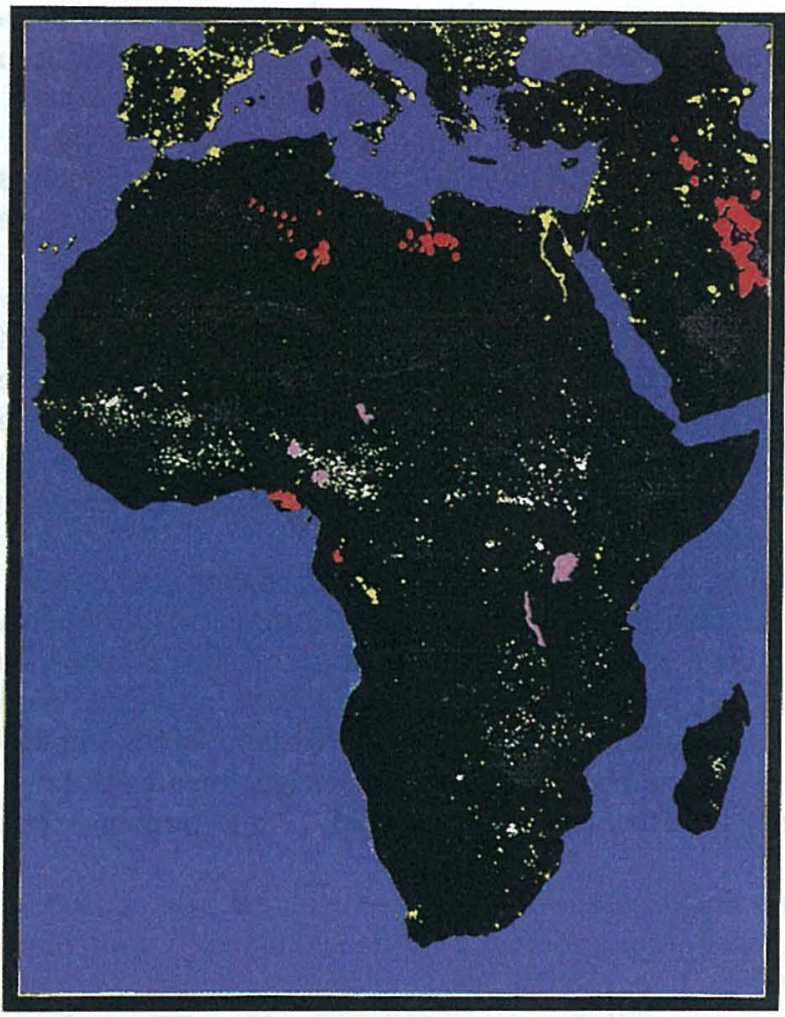

Fig. 6-Fotografia da Terra obtida por um satélite durante a noite 
Esta fotografia ilustra de forma dramática a velocidade à qual estamos a destruir os nossos recursos naturais. Prevê-se que daqui a cerca de 100 anos o petróleo, o gás natural e o carvão sejam muito raros no nosso planeta. Ela evidencia também a velocidade da deflorestação: só neste século foram queimadas cerca de $40 \%$ das nossas florestas. E ainda o excesso de pesca: tem-se pescado tão exageradamente que, por exemplo, o bacalhau já quase desapareceu do Atlântico.

Se compararmos o estado do planeta em 1900 e hoje (no início do século XXI), observamos uma deterioração tão vasta que devemos ficar preocupados com o estado da Terra em 2100. A este ritmo, o nosso planeta ficará inabitável dentro de muito pouco tempo. Estamos em vias de enfrentar a pior crise com que a humanidade algum dia se deparou.

Nós somos o mais poderoso, efectivo e eficiente produto da evolução; nenhum outro organismo tem sido capaz de interagir tão fortemente com o seu ambiente. Desenvolvemos estas dádivas da natureza; tornámo-nos espectadores da natureza e de nós próprios. Mas, nesta altura, estamos perante o facto de que, apesar de termos dominado as forças da natureza de forma bem mais completa do que qualquer outro organismo, não sabemos se poderemos controlar o nosso domínio dessas forças. Poderemos nós evitar a nossa autodestruição?

Esta não é a primeira crise deste tipo com que nos deparámos. Existiu, naturalmente, a crise das bombas atómicas, que entre 1950 e 1980 poderia ter levado ao extermínio da vida na Terra se se tivesse desencadeado uma guerra entre a URSS e os EUA. Naquele tempo vivemos sob a ameaça daquilo que mais tarde ficou conhecido por idade do terror nuclear. Já conhecemos situações nas quais a maior parte da vida na Terra poderia ter desaparecido.

Felizmente, hoje em dia este não é um problema tão crítico. Não vislumbramos actualmente nenhum cenário plausível de guerra nuclear global. A Índia e o Paquistão podem estar a construir bombas, mas não se espera que tal facto conduza a uma guerra mundial. No entanto, descobrimos entretanto que existe um outro modo de nos autodestruirmos, que demora mais tempo, mas que pode ser igualmente eficaz: o aumento da poluição industrial a nível mundial. O que podemos fazer a este respeito?

Hoje em dia as pessoas falam sobre ecologia, mas, quando é chegada a hora de fazer algo, preferem falar de economia. A conferência do Rio de Janeiro é um bom exemplo desta maneira de pensar. Tratou-se de uma conferência maravilhosa, onde cada país foi verde e cheio de boas intenções, mas um relatório intitulado «Rio de Janeiro, cinco anos depois» mostrou que mais de oitenta por cento das promessas então feitas nunca 
foram realmente levadas a sério. Na mais recente conferência de Quioto sobre ar limpo, os Estados Unidos - o maior poluidor da atmosfera a nível mundial - recusaram-se no fundo a tomar as medidas necessárias para resolver o problema.

Para terminar, gostaria de realçar a profunda relação da astronomia com a ecologia. A partir da astronomia pudemos descobrir que a história do universo é o desenvolvimento da complexidade, até um ponto em que o sistema mais organizado se tornou tão poderoso que é capaz de pôr em causa a sua própria existência.

Poderemos nós dominar o nosso próprio poder? Poderemos manter a Terra habitável? A resposta está nas nossas mãos!

É importante para cada um de nós tornar esta mensagem audível em todos os lugares, especialmente pelos políticos. Todos os governos sonham com um crescimento económico forte. Eles têm de perceber que o único crescimento económico compatível com a saúde do nosso planeta é o crescimento zero.

A anedota seguinte expressa a diferença entre o optimista e o pessimista. O pessimista diz: a situação está má, muito má, não poderia estar pior; o optimista responde sim, é verdade. Neste sentido, é nosso dever permanecer optimistas. Não é ainda, felizmente, demasiado tarde para reverter a situação e mostrar, pelo nosso exemplo, que a complexidade não está ameaçada, e que existe, portanto, um futuro. 
 \\ A palavra "fronteiras" pode ser tomada em} diferentes sentidos. Pode referir-se aos limites, necessariamente provisórios, entre o conhecido e o desconhecido, ou aos limites entre o possivel e o impossivel, e, dentro do possivel, entre o desejável e 0 indesejável. Fronteiras podem também ser as delimitações, nem sempre nítidas, entre ciência e não-ciência, e dentro da ciência, entre as várias disciplinas. Quais são então as fronteiras da ciência?

Neste livro, a resposta a esta pergunta é dada, segundo as mais diferentes perspectivas, por um conjunto notável de personalidades, cientistas ou não, entre as quais se contam três Prémios Nobel.

Rui Fausto, Carlos fiolhais e JoÃo Fillipe Queiró são, respectivamente, professores de Química, Física e Matemática na Faculdade de Ciências e Tecnologia da Universidade de Coimbra. 